\title{
Nucleolus organizer regions, types of association and identification of carrier chromosomes in domestic sheep
}

\author{
M Moreno-Millán*, A Rodero-Franganillo \\ Universidad de Córdoba, Facultad de Veterinaria, Departamento de Genética y Mejora \\ Laboratorio de Citogenética, 14005 Cordoba, Spain
}

(Received 20 November 1989; accepted 15 May 1990)

Summary - The frequency of chromosomes carrying nucleolus organizer regions (NORpositive) and the percentage of association between these chromosomes were determined in sheep metaphase spreads. The sequential R-NOR banding technique permitted identification of the chromosome regions involved as the telomeric ends of chromosomes $1(1 \mathrm{p})$, $2(2 q), 3(2 q), 4$ and 25 .

nucleolus organizer regions / sequential R-NOR banding / sheep

Résumé - Régions de l'organisateur nucléolaire, types d'associations et d'identification des chromosomes porteurs chez le mouton. La fréquence de chromosomes porteurs de la région d'organisation nucléolaire (NOR) et le pourcentage d'association entre chromosomes NOR-positifs ont été étudiés chez le mouton. La méthode de marquage séquentiel $R-N O R$ a permis d'identifier comme régions chromosomiques impliquées, les télomères des chromosomes 1 (1p), $2(2 q), 3(3 q)$, \& et 25.

régions de l'organisateur nucléolaire / bandes séquentielles R-NOR / mouton

\section{INTRODUCTION}

The silver-staining technique developed by Goodpasture and Bloom (1975) permitted the differential staining of chromosome proteins from particular regions of the chromosome, the nucleolus organizer regions. Miller et al (1976) showed that only the active NORs were stained with silver in human-mouse somatic cell hybrids.

In domestic sheep, the NORs are located in the telomeric regions of 5 pairs of chromosomes. In this paper, the frequency distribution of these chromosomes is determined, and the NOR-carrier chromosomes are identified using the R-NOR sequential banding technique.

\footnotetext{
* Correspondence and reprints
} 


\section{MATERIALS AND METHODS}

Blood samples were collected from the jugular vein of 12 Spanish Merino sheep and cultured with autologous plasma as a modification of the original whole blood culture method described by De Grouchy et al (1964). The metaphase spreads were banding using the R-NOR banding technique developed by Di Berardino et al (1985). The number of metaphase spreads examined per animal varied from 10-30, and for each spread, the number of NOR-positive chromosomes was recorded. The preparations were examined under UV light and micrographs of the best R-banded metaphases were taken using Kodalith film and printed on Valca No 2 paper.

\section{RESULTS AND DISCUSSION}

The R-NOR sequential banding technique permitted identification of the positive Ag-NOR chromosomes of sheep (fig 1). The nucleolus organizer regions are located on the telomeric ends of 2 acrocentric ( 4 and 25$)$ and 3 metacentric chromosomes $(1 \mathrm{p}, 2 \mathrm{q}$, and $3 \mathrm{q})$.

The frequency of NOR positive chromosomes varied between individuals (table I). The number of NORs per metaphase varied from 5-7.71, with an average of 6.31 NORs/metaphase. These results are similar to those reported in cattle (Mayr et $a l, 1987)$, and in goats (Moreno-Millán and Rodero, 1988a), but appear lower than those reported in sheep ( 8 NORs/metaphase) by Henderson and Bruere (1977). Individual variations in the number of chromosomes showing active NORs have already been reported in humans, pigs, cattle, horses and goats (Goodpasture $\mathrm{et} \mathrm{al}$, 1976; Ray and Pearson, 1979; Stefanova, 1983; Mayr et al, 1987; Kopp et al, 1988; Moreno-Millán and Rodero, 1988a).

Table I. Mean number and standard error (SE) of Ag-NORs per metaphase in 12 sheep.

\begin{tabular}{llll}
\hline Animal No & No Metaphases & Mean No Ag-NOR & SE \\
\hline 1 & 15 & 5.66 & 0.43 \\
2 & 12 & 5.17 & 0.76 \\
3 & 26 & 6.69 & 0.34 \\
4 & 17 & 5.00 & 0.31 \\
5 & 16 & 7.19 & 0.29 \\
6 & 23 & 7.44 & 0.24 \\
7 & 17 & 6.70 & 0.44 \\
8 & 18 & 5.83 & 0.46 \\
9 & 22 & 5.55 & 0.42 \\
10 & 26 & 5.42 & 0.30 \\
11 & 30 & 7.37 & 0.31 \\
12 & 24 & 7.71 & 0.36 \\
\hline
\end{tabular}

Variations in the number of chromosomes showing positive NOR-staining occurred also in the metaphase spreads from the same animal (table I). In some metaphase spreads, both homologous chromosomes were stained, whereas in others 

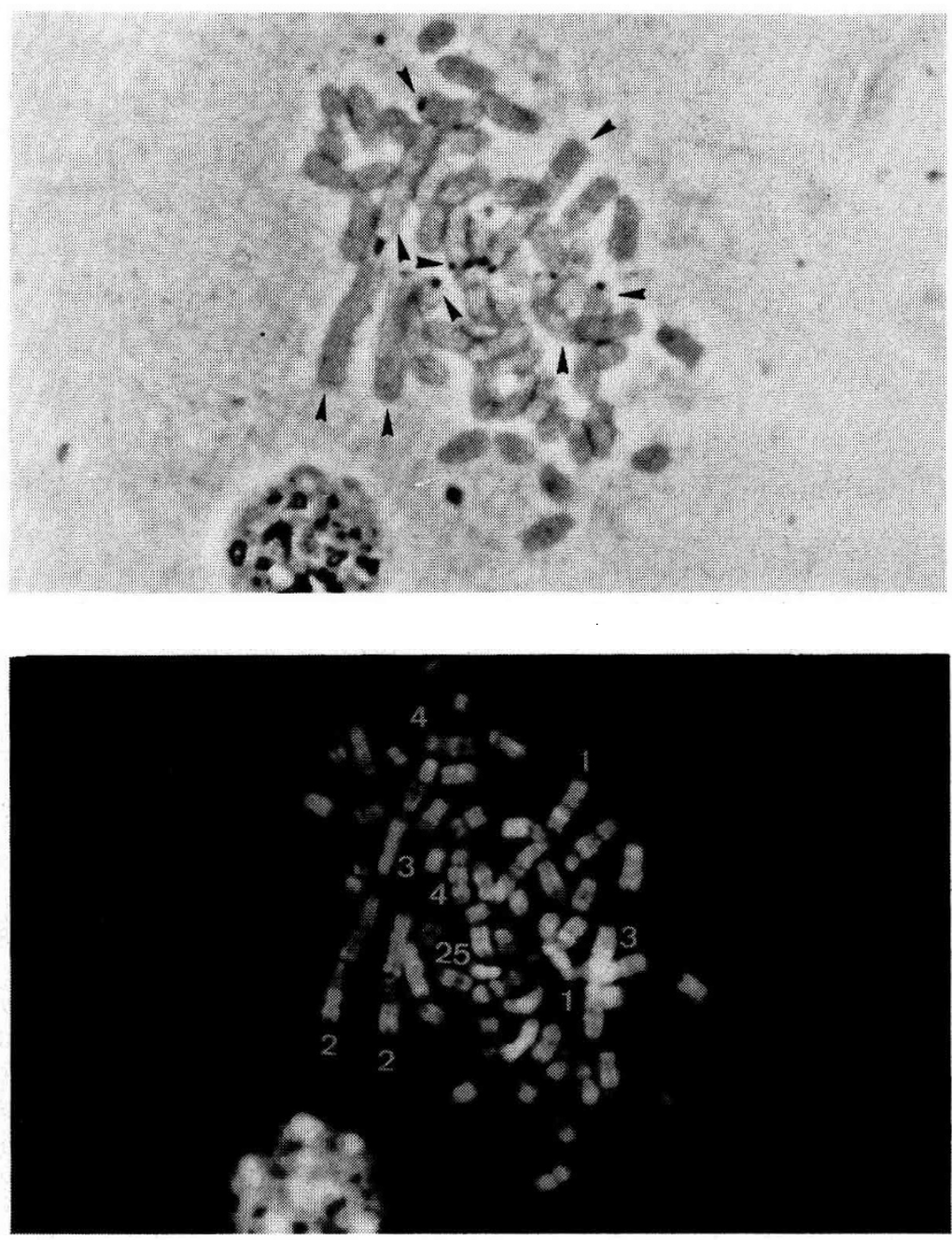

Fig 1. Sequential R-NOR banding in sheep: a) The NOR-active carrying chromosomes are indicated by arrows. b) R-banding of the same metaphase.

only one chromosome of a given pair was NOR-positive. This variability has already been observed in cattle, goats, horses and humans (Mikelsaar et al, 1977; Mayr et al, 1987; Kopp et al, 1988; Moreno-Millán and Rodero, 1988a).

The frequency of total NORs per metaphase showed a trimodal distribution of 4, 6 and 8 positive NORs per cell (table II). This suggests the presence of different peripheral blood lymphocyte (PBL) populations, with a selective advantage given to the 3 types noted in culture. Similar results were obtained in cattle (Mayr et al, 
Table II. Frequency of Ag-NORs per metaphase.

\begin{tabular}{lc}
\hline Ag-NORs No & No metaphases \\
\hline 2 & 2 \\
3 & 12 \\
4 & 41 \\
5 & 21 \\
6 & 55 \\
7 & 32 \\
8 & 61 \\
9 & 12 \\
10 & 10 \\
\hline
\end{tabular}

Table III. Distribution of the chromosomes involved in associations $\left(\chi^{2}, P<0.05\right)$.

\begin{tabular}{lccc}
\hline Chromosomes No & Obs & Exp & $\chi^{2}$ \\
\hline 1 & 29 & 31.2 & 0.16 \\
2 & 13 & 31.2 & $10.62^{*}$ \\
3 & 17 & 31.2 & 6.46 \\
4 & 57 & 31.2 & $21.33^{* * *}$ \\
25 & 40 & 31.2 & 2.48 \\
Total & & & \\
\hline
\end{tabular}

1987), but as noted in this study, this trimodal distribution did not occur in specific animals.

The average rate of association between Ag-NOR-positive chromosomes was 0.30 per metaphase, and could be divided into associations between 2 or 3 chromosomes (average rates of 0.28 and 0.20 , respectively). This association rate is lower than that observed in goats (Moreno-Millán and Rodero, 1988b). Preferential association between certain chromosomes was noted (table III) whereas random association had been noted by Henderson and Bruere (1977). In cattle, Mayr and Schleger (1982) observed random association of chromosomes in only 1 of the 3 breeds investigated.

Associations between chromosomes appears to reflect the dynamic formation of the nucleolus (Henderson and Bruere, 1977). However, an increase in the amount of rDNA in the chromosomes seems to be correlated with an increased frequency of association, resulting also in a greater activity and increased silver staining (Henderson et al, 1973; Warburton et al, 1976; Millet et al, 1977). These aspects are currently being investigated, in association with studies on the transmission patterns of NOR frequency distribution in sheep, to give an overall picture of NORs in sheep karyotype. 


\section{REFERENCES}

De Grouchy J, Roubin M, Passage E (1964) Microtechnique pour l'étude des chromosomes humains à partir d'une culture de leucocytes sanguins. Ann Génét 7, 45-46

Di Berardino D, Lioi MB, Iannuzzi L (1985) Identification of nucleolus organizer chromosomes in cattle (Bos taurus L) by sequential silver staining + RBA bandings. Caryologia 38, 95-102

Goodpasture C, Bloom SE (1975) Visualization of nucleolus organizer regions in mammalian chromosomes using silver staining. Chromosoma 53, 37-50

Goodpasture C, Bloom SE, Hsu TC, Arrighi FE (1976) Human nucleolus organizer: the satellites of the stalks. Am J Hum Genet 28, 559-566

Henderson AS, Warburton D, Atwood KC (1973) Ribosomal DNA connectives between human acrocentric chromosomes. Nature 245, 95-97

Henderson LM, Bruère AN (1977) Association of nucleolus organizer chromosomes in domestic sheep (Ovis aries) shown by silver staining. Cytogenet Cell Genet $19,326-334$

Kopp E, Mayr B, Kalat M, Schleger W (1988) Polymorphisms of NORs and heterochromatin in the horse and donkey. $J$ Hered $79,332-337$

Mayr B, Schleger W (1982) Association patterns in cattle chromosomes. $J$ Hered $73,468-470$

Mayr B, Schleger W, Auer H (1987) Frequency of Ag-stained nucleolus organizer regions in the chromosomes of cattle. J Hered 78, 206-207

Mikelsaar AV, Schmid M, Krone W, Schwarzacker HG, Schnedl W (1977) Frequency of Ag-stained nucleolus organizer regions in the acrocentric chromosomes of man. Hum Genet 37, 73-77

Miller DA, Dev VG, Tantrahavi R, Miller OJ (1976) Suppression of human nucleolus organizer activity in mouse-human somatic hybrid cells. Exp Cell Res 101, 235243

Miller DA, Tantrahavi R, Dev VG, Miller OJ (1977) Frequency of satellite associations of human chromosomes is correlated with the amount of Ag-staining of the nucleolus organizer regions. Am J Hum Genet 29, 480-502

Moreno-Millán M, Rodero A (1988a) Frequency of active nucleolus organizer regions in domestic goats. In: 8th Eur Colloq Cytogenet Domestic Animals, Bristol, July 19-22, 1988 (Long SE, ed) 87-91, Department of Animal Husbandry, Univ Bristol

Moreno-Millán M, Rodero A (1988b) NOR-association patterns in goat chromosomes. In: 8th Eur Colloq Cytogenetic Domestic Animals, Bristol, July 19-22, 1988 (Long SE, ed), Department of Animal Husbandry, Univ Bristol, 83-86

Ray M, Pearson J (1979) Nucleolar organiser regions of human chromosomes. Hum Genet 48, 201-210

Stefanova VN (1983) Polymorphism of nucleolus organizer regions in the chromosomes of the domestic pig. Citologija 25, 189-193

Warburton D, Atwood KC, Henderson AS (1976) Variation in the number of genes for rDNA among human acrocentric chromosomes: correlation with frequency of satellite association. Cytogenet Cell Genet 17, 221-230 